\title{
FORMER PRESIDENTS
}

J. H. Van Amringe, 1889-1890.

Emory McClintock, 1891-1894.

G. W. Hill, 1895-1896.

Simon Newcomb, 1897-1898.

R. S. Woodward, 1899-1900.

E. H. Moore, 1901-1902.

T. S. Fiske, 1903-1904.

W. F. Osgood, 1905-1906.

H. S. White, 1907-1908.

Maxime Bôcher, 1909-1910.

H. B. Fine, 1911-1912.

E. B. Van Vleck, 1913-1914.

E. W. Brown, 1915-1916.

L. E. Dickson, 1917-1918.
Frank Morley, 1919-1920.

G. A. Bliss, 1921-1922.

Oswald Veblen, 1923-1924.

G. D. Birkhoff, 1925-1926.

Virgil Snyder, 1927-1928.

E. R. Hedrick, 1929-1930.

L. P. Eisenhart, 1931-1932.

A. B. Coble, 1933-1934.

Solomon Lefschetz, 1935-1936.

R. L. Moore, 1937-1938.

G. C. Evans, 1939-1940.

Marston Morse, 1941-1942.

M. H. Stone, 1943-1944.

\section{ENDOWMENT FUND}

In 1923 an Endowment Fund was collected to meet the greater demands on the Society's publication program caused by the ever increasing number of important mathematical memoirs. Of this fund, which now amounts to some $\$ 71,000$, a considerable proportion was contributed by members of the Society. Under the terms of the will of the late Robert Henderson, for many years a Trustee of the Society, the Society receives approximately $\$ 4,000$ yearly. Upon the death of the other legatees, the Society will receive the entire principal of the estate for its Endowment Fund.

\section{SPECIAL FUNDS}

\section{The Bôcher Memorial Prize.}

This prize was founded in memory of Professor Maxime Bôcher. It is awarded every five years for a notable research memoir in analysis which has appeared during the preceding five years in a recognized journal published in the United States or Canada; the recipient must be a member of the Society, and not more than fifty years old at the time of publication of his memoir.

First (Preliminary) Award, 1923: To G. D. Birkhoff, for his memoir Dynamical systems with two degrees of freedom.

Second Award, 1924: To E. T. Bell, for his memoir Arithmetical paraphrases, and to Solomon Lefschetz, for his memoir On certain numerical invariants with applications to abelian varieties. situs.

Third Award, 1928: To J. W. Alexander, for his memoir Combinatorial analysis

Fourth Award, 1933: To Marston Morse, for his memoir The foundations of a theory of the calculus of variations in the large in $m$-space, and to Norbert Wiener, for his memoir Tauberian theorems.

Fifth Award, 1938: To John von Neumann, for his memoir Almost periodic functions and groups.

Sixth Award, 1943: To Jesse Douglas, for his memoirs Green's function and the 
problem of Plateau, The most general form of the problem of Plateau, and Solution of the inverse problem of the calculus of variations.

\section{The Frank Nelson Cole Prize in Algebra. The Frank Nelson Cole Prize in the Theory of Numbers.}

These prizes were founded in honor of Professor Frank Nelson Cole, on the occasion of his retirement as Secretary of the American Mathematical Society and Editor of the Bulletin, after twenty-five years of service; the fund was later doubled by his son, Charles A. Cole. They are awarded at five-year intervals for contributions to algebra and the theory of numbers, respectively, under restrictions similar to those for the Bôcher prize.

First Award, 1928: To L. E. Dickson, for his book Algebren und ihre Zahlentheorie, Zurich, 1927.

Second Award, 1931: To H. S. Vandiver, for his several papers on Fermat's last theorem published in the Transactions of the American Mathematical Society and the Annals of Mathematics during the last five years, with special reference to a paper entitled On Fermat's last theorem, which appeared in volume 31 of the Transactions.

Third Award, 1939: To A. A. Albert, for his papers on the construction of Riemann matrices, published in volumes 35 and 36 of the Annals of Mathematics.

Fourth Award, 1941: To Claude Chevalley, for his paper entitled La theorie du corps de classes, published in volume 41 of the Annals of Mathematics.

Fifth Award, 1944: To Oscar Zariski, for four papers on algebraic varieties, published in volumes 61 and 62 of the American Journal of Mathematics and volumes 40 and 41 of the Annals of Mathematics.

\section{The Eliakim Hastings Moore Fund.}

This fund was founded in 1922 in honor of Professor Eliakim Hastings Moore, on the occasion of the twenty-fifth anniversary meeting of the Chicago Section of the American Mathematical Society. The income from the fund is to be used, at the discretion of the Council of the Society, for the publication of important mathematical books or memoirs, or the award of prizes.

\section{The Marion Reilly Fund.}

Dean Marion Reilly willed to the American Mathematical Society a portion of her estate to be used for the advancement of research in pure mathematics. The principal of this fund is $\$ 23,500$.

\section{The Ernest William Brown Fund.}

From the estate of Professor Ernest William Brown, a fund of $\$ 1,000$ is available, the interest on which, at the discretion of the Council, can be used for the furtherance of such mathematical interests as (a) the publication of important mathematical books, memoirs, and periodicals, and (b) lectures to be delivered on special occasions by invited guests of the Society.

\section{The Robert Henderson Fund.}

Upon his retirement from the Board of Trustees on December 31, 1940, Dr. Robert Henderson presented to the Society an unrestricted gift of $\$ 1,000$ which the Trustees have set aside as the Robert Henderson Fund. 